\title{
BNCC PARA A EDUCAÇÃO INFANTIL: é ou não é currículo?
}

\author{
Roselane Fátima Campos \\ Universidade Federal de Santa Catarina - UFSC \\ Zenilde Durli \\ Universidade Federal de Santa Catarina - UFSC
}

\begin{abstract}
Resumo
Com foco nas questões curriculares, o artigo focaliza a BNCC para a Educação Infantil, traçando comparativo entre as várias versões construídas no processo. Analisa possíveis implicações de algumas das mudanças efetuadas nos documentos, nos seguintes aspectos: a mudança no princípio articulador geral do documento de "direitos de aprendizagem e desenvolvimento" para “competências gerais e específicas”; o deslocamento da noção de experiência enquanto dimensão intrínseca à aprendizagem e ao desenvolvimento, com foco no sujeito, para componente do arranjo curricular sob a denominação de campos de experiência e, ainda, o uso dos objetivos de aprendizagem enquanto formas de operacionalizar as competências a serem alcançadas pelas crianças. Trata-se de um estudo documental, desenvolvido por meio da técnica de análise de conteúdo. Nas considerações finais, apresenta argumentos sobre a prescrição curricular e a iminência de perspectivas de escolarização na Educação Infantil.
\end{abstract}

Palavras-chave: currículo; base nacional comum curricular; educação infantil.

\begin{abstract}
The purpose of this article is to analyze the BNCC for Early Childhood Education, drawing a comparing between the various versions of the documents that preceded the one approved. This is a documentary study which, through content analysis, highlights the following implications: the change in the general articulating principle of the document "rights of learning and development" to "general and specific competences"; from the displacement of the notion of experience as an intrinsic dimension of learning and development, with a focus on the subject, to a component of the curricular arrangement under the denomination of fields of experience as well as the use of the objectives of learning as forms of operationalizing the competencies to be attained by the children. In the final considerations we analyze the curricular prescription and the imminence of schooling in Childhood Education.
\end{abstract}

Keywords: curriculum; national common curriculum base; eary childhood education. 


\section{Introdução}

Em sessão pública realizada no dia 15 de dezembro de 2017, o Conselho Nacional de Educação (CNE) apreciou e votou o Parecer CNE/CP no 15/2017 (BRASIL, 2017a) e a Resolução CNE/CP no 02/2017 (BRASIL, 2017b), relativos à Base Nacional Comum Curricular (BNCC) da Educação Infantil e do Ensino Fundamental. Na sequência, pela Portaria Ministerial $n^{\circ}$ 1.570, ela foi homologada e publicada no Diário Oficial da União em 21/12/2017 (BRASIL, 2017c).

Apesar de ser apresentada como uma "novidade" e de ter sua necessidade justificada em discursos de justiça social, equidade, qualidade da educação e, sobretudo, na ideia de oportunidades iguais para todos, pilares básicos do pensamento meritocrático, a "Base”, de fato, não é novidade. Desde os currículos mínimos obrigatórios no período do regime militar até os governos da década de 1990 em diante vários foram os movimentos e iniciativas de implementação de currículos de abrangência nacional. Relembramos iniciativas como os Parâmetros Curriculares Nacionais (PCN) e Referenciais Curriculares Nacionais para a Educação Infantil (RCNEI) ${ }^{1}$, Programa Currículo em Movimento², além de outros programas centrados em um ou em outro aspecto de conteúdo ou dimensões curriculares. Pode-se mesmo dizer que o processo que culminou com a aprovação da BNCC foi iniciado já com as discussões da Constituição (1988), prosseguindo com a Lei de Diretrizes e Bases da Educação Nacional (LDBEN) 9.394/1996 e, também, com os Planos Nacionais de Educação (PNE 2001-2011; 2014-2024). Dado seu caráter regulador, coube ao Conselho Nacional de Educação (CNE) estabelecer e atualizar o conjunto de diretrizes curriculares para todos os níveis, etapas e modalidades da educação brasileira. Ora, sendo este o contexto, cabe-nos perguntar: a que se deve o sentido de necessidade e de urgência com que foi tratada a BNCC?

Os debates acerca de um currículo nacional ganharam força com o Plano Nacional de Educação (2014-2024), quando novos e velhos atores/ sujeitos sociais e sujeitos coletivos passaram a disputar - sob uma nova agenda -, também a questão curricular. Destaque-se aqui a forte presença empresarial, incluindo bancos, empresas e organizações e/ou fundações, organizadas em redes - como Fundação Leman, Movimentos Todos Pela Educação, Instituto Ayrton Senna, Fundação Maria Cecília Vidigal -, além de grupos neoconservadores que se empenharam em ter suas pautas de caráter moral atendidas. Foram estes os principais protagonistas e interlocutores do governo, em particular de 2016 em diante, nos debates e ações que culminaram com a homologação da BNCC para a educação básica.

Uma agenda foi consensuada entre estes atores cujo ponto de partida é o diagnóstico acerca da crise da educação, situada apenas na qualidade da mesma e, mesmo esta, reduzida à relação ensino-aprendizagem. O receituário que defendem como condição necessária para alavancar a educação no país centra-se no controle curricular e nas avaliações em larga escala. Se esta é a receita, todavia, os interesses que a movem são muitos, todos relacionados à privatização da educação, em suas diferentes formas (BALL, 2004). Mas, de fato, o mais premente de todos é a produção de uma nova subjetividade, a formação de um 
novo tipo de trabalhador mais adequado às demandas atuais do capital. Isso pode ser observado desde os princípios orientadores da BNCC até os conteúdos previstos ou excluídos da mesma, em particular quando consideramos a BNCC para o ensino médio, posteriormente aprovada. Cotejados os documentos da Base para as três etapas da educação básica, esse projeto de formação fica evidente.

Nosso objetivo nesse artigo é trazer à discussão a BNCC para a Educação Infantil, por meio de estudo documental e da técnica de análise de conteúdo (BARDIN, 1979), traçando uma análise comparativa entre as várias versões dos documentos que antecederam àquele aprovado, evidenciando como as mudanças ocorridas foram esculpindo-a de modo a ajustar-se ao projeto de formação traçado para as demais etapas. Salientamos as implicações desse alinhamento na mudança do princípio articulador geral do documento de “direitos de aprendizagem e desenvolvimento" para as "competências gerais e específicas”; no deslocamento da noção de experiência enquanto dimensão intrínseca à aprendizagem e ao desenvolvimento, com foco no sujeito, para componente do arranjo curricular sob a denominação de campos de experiência e, ainda, no uso dos objetivos de aprendizagem enquanto formas de operacionalizar as competências a serem alcançadas pelas crianças. Por fim, nas considerações finais, analisamos a prescrição curricular e a iminência da escolarização da Educação Infantil provocadas pela BNCC no seu formato atual.

\section{Quatro versões da BNCC: da aprendizagem como direito ao desenvolvimento de competências}

Muito embora o texto da BNCC faça referências a Constituição Federal e a LDBEN 9394/96, usando-os como justificativa para a mesma, conforme bem aponta Aguiar (2018), estes documentos se referem a “formação básica comum”, inexistindo ali qualquer menção de que isto signifique um currículo padronizado em nível nacional. Ou seja, a expressão e determinação para que tenhamos uma "base nacional comum curricular” aparece, de fato, no PNE (2014- 2024), documento este no qual se opera uma "transmutação da base nacional comum em base nacional comum curricular” (AGUIAR, 2018, p. 726). Ainda segundo a autora, também no PNE (BRASIL, 2014) outras “transmutações” ou ressignificações ocorreram, como por exemplo a estratégia 2.1 da meta 2, que trata da elaboração de uma proposta a ser encaminhada ao CNE "de direitos e objetivos de aprendizagem e desenvolvimento para os(as) alunos (as) do ensino fundamental”. Em seguida, na estratégia 2.2, diz-se que os direitos e objetivos de aprendizagem e desenvolvimento configurarão a base nacional comum curricular do ensino fundamental. Pouco depois, na meta 3, estratégia 3.2, vincula a formulação de direitos e objetivos de aprendizagem e desenvolvimento para jovens do ensino médio à uma "formação básica comum”. Em seguida, observa-se, tal como na estratégia 2.3 do ensino fundamental, a vinculação destes (direitos e objetivos) com uma base nacional comum curricular (estratégia 3.3). 
Como vemos, os litígios ocorridos pelas forças sociais em presença por ocasião da elaboração e aprovação do PNE (2014), expressou-se em contradições e fissuras que, a rigor, permanecem presentes nos debates atuais acerca da BNCC. Evidentemente que são bastante distintos os significados e sentidos dos termos "formação básica comum", "base nacional comum" e "base nacional comum curricular". A adição do termo "curricular" associado ao "comum" resultou na promulgação de um currículo nacional padronizado para todas as etapas da educação básica, cujos efeitos, em termos de formação das crianças e jovens e de política educacional, não são difíceis de prever.

No que tange especificamente à Educação Infantil, causa de fato estranheza sua incorporação à BNCC, posto que nada consta nos documentos normativos que a antecederam, o que em tese justificaria sua inserção, nada relativo ao estabelecimento de um currículo nacional para esta etapa educativa. O art. 26, da LDBEN 9394/96, faz menção a ter-se uma "base nacional comum" na Educação Infantil, o que já está suficientemente atendido pelas DCNEI (2009); o mesmo pode-se dizer do PNE (2014 - 2024), onde nada encontramos acerca de exigência desse tipo. Observe-se o que diz a estratégia 7.1, da meta 7:

estabelecer e implantar, mediante pactuação interfederativa, diretrizes pedagógicas para a educação básica e a base nacional comum dos currículos, com direitos e objetivos de aprendizagem e desenvolvimento dos (as) alunos (as) para cada ano do ensino fundamental e médio, respeitada a diversidade regional, estadual e local.” (Sem grifos no original.).

Ora, assim, se a necessidade de uma BNCC foi sendo construída e justificada pela ressignificação discursiva nos termos das leis, operação semelhante observamos também quando se trata dos "direitos e objetivos de aprendizagem e desenvolvimento". Conforme registrado no documento "Por uma política curricular para a educação básica: contribuição ao debate da base nacional comum a partir do direito à aprendizagem e ao desenvolvimento" (BRASIL, 2014), uma das polêmicas centrais originada nas discussões foi sobre a adoção do termo "expectativas de aprendizagem"3. Para alguns membros do GT $^{4}$ adotá-lo significava imputar "um conjunto de obrigações [...] somente aos estudantes para a consolidação das tarefas, finalidades e resultados escolares em um contexto de permanente culpabilização destes, de suas famílias e de seu contexto sócio-cultural" (BRASIL, 2014, p. 7). Como decorrência o GT passou a trabalhar com a perspectiva de "direitos à aprendizagem e ao desenvolvimento", por entender que ela incluiria o debate acerca das condições através das quais o "Estado brasileiro tem garantido, ou não, as possibilidades para que as tarefas, finalidades e resultados escolares sejam efetivados de modo positivo na vida dos estudantes no cotidiano da instituição escolar” (Idem.).

A primeira versão BNCC-I ${ }^{5}$ para a Educação Infantil, diferentemente das demais etapas da Educação Básica, no que concerne à organização curricular, articulou-se a partir de seis direitos de aprendizagem: conviver, brincar, participar, explorar, comunicar e conhecer-se, desdobrados em objetivos de aprendizagem, agrupados por campos de 
experiências, a saber: 1) o eu, o outro e o nós; 2) corpo, gestos e movimentos; 3) escuta, fala, pensamento e imaginação; 4) traços, sons, cores e imagens; 5) espaços, tempos, quantidades, relações e transformações.

Esta estrutura básica foi mantida na segunda versão, a BNCC-II, datada de abril de 2016, chamando à atenção a inclusão de cortes etários: "bebês" (0 a 18 meses), "crianças bem pequenas" (19 meses a 3 anos e 11 meses), "crianças pequenas" (4 anos a 5 anos e 11 meses). Esta inclusão aproxima o modelo curricular da Educação Infantil daqueles propostos para as demais etapas da educação básica, ainda que se chame a atenção para os limites envolvidos quando se define objetivos a serem alcançados em cada idade.

Este documento, que na sequência foi objeto de ajustes atendendo indicações de especialistas, consultores e leitores críticos, deveria ser encaminhado para apreciação do CNE até julho de 2016. No entanto, com o golpe jurídico-parlamentar que destituiu a presidenta Dilma Rouseff e a consequente reestruturação do governo, apenas em abril de 2017 o Conselho recebeu o documento da BNCC, ou seja, uma terceira versão, com modificações substanciais com relação as duas versões anteriores, evidenciando a intervenção do MEC, com vistas 'corrigir' os rumos do que vinha sendo feito [...] e adequar a base ao enfoque dos novos ocupantes do ministério" (FREITAS, 2016). ${ }^{6}$

Para além da subtração de toda a parte relativa ao Ensino Médio, a organização da Base em competências gerais e específicas, assim como a inclusão das competências socioemocionais, marcou o explícito rompimento com versões anteriores. Competências gerais - cognitivas, comunicativas, pessoais e sociais - passaram a ser referência à definição de competências para cada área e componente curricular, conformando o seguinte percurso: competências gerais => competências de área => competências do componente => objetivos de aprendizagem. Todos os objetivos de aprendizagem foram revisados, alguns incluídos e outros excluídos, a partir dos seguintes parâmetros: clareza, pertinência e progressão das aprendizagens, conforme orientações do Movimento pela Base) ${ }^{7}$. Evidentemente, tais parâmetros tiveram como lógica a métrica das avaliações em larga escala.

Polêmica, a BNCC-III manteve os seis direitos específicos da EI e, também, os campos de experiências, com alterações na denominação de dois deles: de "traços, sons, formas e imagens" para "Traços, sons, cores e formas" e de "Escuta, fala, linguagem e imaginação" para "Oralidade e escrita". Podemos creditar estas mudanças ao protagonismo assumido pelo Movimento Pela Base (MPB) que, em análise datada de dezembro de 2015, relativa à primeira versão, já ressaltava: "é importante incorporar elementos do desenvolvimento da linguagem oral e escrita desde a Educação Infantil, criando as bases para o trabalho de alfabetização no ensino fundamental [...]” (MPB, 2015, s/p). O documento trata da progressão da Educação Infantil para o ensino fundamental e explicita quais elementos servem como fundamento ao letramento nos anos iniciais. À tese de escolarização cabe ainda observar o significativo reforço nos objetivos dos campos de experiências mais ligados às áreas da leitura, escrita e matemática em detrimento do equilíbrio verificado nas versões anteriores. Cabe destacar ainda que essa centralidade coincide com os conhecimentos compósitos das matrizes de referência das avaliações em larga escala. Já no 
que diz respeito aos cortes etários, suprimiu-se os termos "bebês”, “crianças bem pequenas” e “crianças pequenas”, mantendo-se os agrupamentos por idade.

Quando comparada a BNCC-III com a BNCC-IV - versão homologada -, observamos que foi retomada a denominação das faixas etárias conforme constava na BNCC-II, ou seja: Bebês (0 a 18 meses), Crianças bem pequenas (19 meses a 3 anos e 11 meses) e Crianças pequenas (4 anos a 5 anos e 11 meses). A separação e a quantidade de objetivos por campo de experiência foram mantidas de acordo com a terceira versão. Segundo o conselheiro do CNE Ivan Claudio Siqueira ${ }^{8}$ em entrevista por ocasião da aprovação da Base, ao se referir a essa questão, a "régua era muito baixa" (JEDUCA, 2017). O quadro I mostra estas mudanças.

Quadro 1 - Análise comparativa das quatro versões da BNCC - Educação Infantil

\begin{tabular}{|c|c|c|c|c|c|}
\hline VERSÕES & $\begin{array}{c}\text { CAMPOS DE } \\
\text { EXPERIÊNCIAS } \\
\end{array}$ & \multicolumn{3}{|c|}{$\begin{array}{c}\text { Objetivos } \\
\text { de aprendizagem ( }(0-6 \text { anos) }\end{array}$} & Qtd. \\
\hline \multirow{6}{*}{$\begin{array}{l}\text { Primeira } \\
\text { versão } \\
\text { (2015) }\end{array}$} & O eu, o outro, e nós & \multicolumn{3}{|c|}{06} & 06 \\
\hline & $\begin{array}{l}\text { Corpo, gestos e } \\
\text { movimentos }\end{array}$ & \multicolumn{3}{|c|}{06} & 06 \\
\hline & $\begin{array}{l}\text { Traços, sons, cores e } \\
\text { imagens }\end{array}$ & \multicolumn{3}{|c|}{06} & 06 \\
\hline & $\begin{array}{l}\text { Escuta, fala, pensamento e } \\
\text { imaginação }\end{array}$ & \multicolumn{3}{|c|}{06} & 06 \\
\hline & $\begin{array}{l}\text { Espaços, tempos, } \\
\text { quantidades, relações e } \\
\text { transformações }\end{array}$ & \multicolumn{3}{|c|}{06} & 06 \\
\hline & & & & & 30 \\
\hline \multirow{7}{*}{$\begin{array}{l}\text { Segunda } \\
\text { versão } \\
\text { (2016) }\end{array}$} & & $\begin{array}{l}\text { Bebês }(0 \text { a } \\
18 \text { meses })\end{array}$ & $\begin{array}{c}\text { Crianças bem } \\
\text { pequenas } \\
\text { (19 meses a } 3 \\
\text { anos e } 11 \text { meses) }\end{array}$ & $\begin{array}{c}\text { Crianças } \\
\text { pequenas } \\
\text { (4 anos a } 5 \text { anos } \\
\text { e } 11 \text { meses) }\end{array}$ & Qtd: \\
\hline & O eu, o outro, e nós & 05 & 05 & 05 & 15 \\
\hline & $\begin{array}{c}\text { Corpo, gestos e } \\
\text { movimentos }\end{array}$ & 05 & 05 & 05 & 15 \\
\hline & $\begin{array}{c}\text { Traços, sons, formas e } \\
\text { imagens }\end{array}$ & 05 & 05 & 05 & 15 \\
\hline & $\begin{array}{c}\text { Escuta, fala, linguagem e } \\
\text { imaginação }\end{array}$ & 04 & 05 & 05 & 14 \\
\hline & $\begin{array}{c}\text { Espaços, tempos, } \\
\text { quantidades, relações e } \\
\text { transformações }\end{array}$ & 04 & 05 & 05 & 14 \\
\hline & & & & & 73 \\
\hline \multirow{3}{*}{$\begin{array}{l}\text { Terceira } \\
\text { versão } \\
\text { (2017a) }\end{array}$} & & $\begin{array}{l}\text { Crianças de } \\
\text { zero a } 1 \text { ano } \\
\text { e } 6 \text { meses }\end{array}$ & $\begin{array}{l}\text { Crianças de } 1 \text { ano } \\
\text { e } 7 \text { meses a } 3 \text { anos } \\
\text { e } 11 \text { meses }\end{array}$ & $\begin{array}{c}\text { Crianças de } 4 \\
\text { anos a } 5 \text { anos e } \\
11 \text { meses }\end{array}$ & Qtd. \\
\hline & O eu, o outro, e nós & 06 & 07 & 07 & 20 \\
\hline & $\begin{array}{l}\text { Corpo, gestos e } \\
\text { movimentos }\end{array}$ & 05 & 05 & 05 & 15 \\
\hline
\end{tabular}




\begin{tabular}{|c|c|c|c|c|c|}
\hline & $\begin{array}{c}\text { Traços, sons, cores e } \\
\text { formas }\end{array}$ & 03 & 03 & 03 & 09 \\
\hline & Oralidade e escrita & 09 & 09 & 09 & 27 \\
\hline & $\begin{array}{l}\text { Espaços, tempos, } \\
\text { quantidades, relações e } \\
\text { transformações }\end{array}$ & 06 & 08 & 08 & 22 \\
\hline & & & & & 93 \\
\hline \multirow{6}{*}{$\begin{array}{l}\text { Quarta } \\
\text { versão } \\
\text { (2017b) }\end{array}$} & & $\begin{array}{l}\text { Bebês } \\
(0 \text { a } 18 \\
\text { meses })\end{array}$ & $\begin{array}{c}\text { Crianças bem } \\
\text { pequenas } \\
\text { (19 meses a } 3 \\
\text { anos e } 11 \text { meses) }\end{array}$ & $\begin{array}{c}\text { Crianças } \\
\text { pequenas } \\
\text { (4 anos a } 5 \text { anos } \\
\text { e } 11 \text { meses) } \\
\end{array}$ & Qtd. \\
\hline & O eu, o outro, e nós & 06 & 07 & 07 & 20 \\
\hline & $\begin{array}{c}\text { Corpo, gestos e } \\
\text { movimentos }\end{array}$ & 05 & 05 & 05 & 15 \\
\hline & $\begin{array}{l}\text { Traços, sons, cores e } \\
\text { formas }\end{array}$ & 03 & 03 & 03 & 09 \\
\hline & $\begin{array}{c}\text { Escuta, fala, linguagem e } \\
\text { imaginação }\end{array}$ & 09 & 09 & 09 & 27 \\
\hline & $\begin{array}{c}\text { Espaços, tempo, } \\
\text { quantidades, relações e } \\
\text { transformações }\end{array}$ & 06 & 08 & 08 & 22 \\
\hline
\end{tabular}

Fonte: Construído pelas autoras.

Ao analisarmos as quatro versões da BNCC Educação Infantil, podemos constatar um recrudescimento nas concepções ${ }^{9}$ orientadoras derivadas de uma abordagem tecnicista de currículo e de educação. Destacamos em primeiro lugar, sua subordinação a noção de competências, pois embora não oriente de forma direta esta etapa, tal como se constata com relação ao ensino fundamental, de fato, sua lógica encontra-se imiscuída nos objetivos de aprendizagem definidos para cada campo de experiência e faixas etárias e também nas páginas introdutória, em que as concepções orientadoras da BNCC, no seu conjunto, são apresentadas:

Ao longo da Educação Básica, as aprendizagens essenciais definidas na BNCC devem concorrer para assegurar aos estudantes o desenvolvimento de dez competências gerais, que consubstanciam, no âmbito pedagógico, os direitos de aprendizagem e desenvolvimento (BRASIL, 2017a, p. 8).

Note-se, nessa passagem, que os três conceitos alvo de disputas ao longo da elaboração do PNE e da BNCC - aprendizagens essenciais, competências e direitos de aprendizagem , apesar de expressarem concepções distintas e excludentes, são tratados como complementares e harmonicamente articulados, alçados a princípios organizadores do currículo. Dois aspectos são importantes aqui: o caráter pragmático da noção de competências que se expressa "como a mobilização de conhecimentos (conceitos e procedimentos), habilidades (práticas, cognitivas e socioemocionais), atitudes e valores 
para resolver demandas complexas da vida cotidiana, do pleno exercício da cidadania e do mundo do trabalho” (BRASIL, 2017a, p.8), sua perspectiva não de articulação, mas de subordinação dos conteúdos de aprendizagem e dos direitos ao desenvolvimento das mesmas:

É imprescindível destacar que as competências gerais da Educação Básica, apresentadas a seguir, inter-relacionam-se e desdobram-se no tratamento didático proposto para as três etapas da Educação Básica (Educação Infantil, Ensino Fundamental e Ensino Médio), articulando-se na construção de conhecimentos, no desenvolvimento de habilidades e na formação de atitudes e valores, nos termos da LDB (BRASIL, 2017a, p. 8).

Ao conduzir à seleção de conteúdos imediatamente práticos e úteis, a noção de competências impõe um tipo de padrão educacional em detrimento de outros mais significativos ao desenvolvimento integral das crianças e jovens. Por meio desse padrão "dissemina o individualismo como valor moral radical, reduzindo, assim, a função social da escola, da educação e de sua cultura desinteressada”. (PEREIRA, 2016, p. 144)

Para garantir o direito à aprendizagem e ao desenvolvimento e uma educação de qualidade não basta estabelecer um conjunto de competências, sejam elas gerais ou específicas, em um currículo nacional. O direito à educação, conforme determina título específico da LDB, exige que a escola tenha condições de oferecer uma educação com base em determinados padrões de qualidade (CURY, 2014; XIMENES, 2014). Entretanto, a realidade objetiva na qual acontecem os processos de escolarização é muito diversa em relação às condições de acesso, de permanência, de recursos pedagógicos, de formação de professores, isso sem falar nas subjetividades relativas à aprendizagem e ao desenvolvimento.

\section{Experiência e campos de experiências: do sujeito ao componente curricular}

O termo “campos de experiências” é central na Base para a Educação Infantil. Seu uso é justificado pela especificidade que constitui essa etapa educativa, pois diferentemente das demais, não se organiza tendo como referência os conteúdos disciplinares. Tem como inspiração o "modelo" curricular para a Educação Infantil, adotado na Itália (BRASIL, 2016; BARBOSA; RICHTER, 2015) ${ }^{10}$, e toma como pressuposto que as experiências são nucleares aos aprendizados das crianças:

Os campos de experiências constituem um arranjo curricular que acolhe as situações e as experiências concretas da vida cotidiana das crianças e seus saberes, entrelaçando-os aos conhecimentos que fazem parte do patrimônio cultural (BRASIL, 2017d, p.38). 
Todavia, embora este termo seja nuclear na BNCC/EI, na análise que fizemos de todas as versões não o encontramos claramente definido, o mesmo ocorrendo com o conceito de experiência. Apenas na versão II (2016), faz-se referência às indicações curriculares da Itália. Já com relação ao conceito de experiência, identificamos sua base epistemológica filosofia pragmática de Dewey -, ao analisarmos outros materiais produzidos por pesquisadores da área que tratam então, tanto de explicitar o que compreendem como “campo de experiências” e a que conceito de experiência este se articula (BARBOSA; FARIA; FINCO, 2015; FOCCHI, 2015).

Cotejadas as quatro versões da BNCC observamos que este termo foi sofrendo alterações, permanecendo, no entanto, dois sentidos: a) os campos de experiência são usados para referir as particularidades constitutivas dos processos de aprendizagem das crianças pequenas; b) os campos de experiências são tratados como núcleos organizadores do currículo e, nesse sentido, cumprindo a função que os componentes curriculares têm nas demais etapas:

Considerando que, na Educação Infantil, as aprendizagens e o desenvolvimento das crianças têm como eixos estruturantes as interações e as brincadeiras [...] A organização curricular da Educação Infantil na BNCC está estruturada em cinco campos de experiências, no âmbito dos quais são definidos os objetivos de aprendizagem e desenvolvimento. Os campos de experiências constituem um arranjo curricular que acolhe as situações e as experiências concretas da vida cotidiana das crianças e seus saberes, entrelaçando-os aos conhecimentos que fazem parte do patrimônio cultural. (BRASIL, 2017d, p. 38. Grifo no original.)

Se nas versões que precederam o documento aprovado a criança e a particularidade de seus processos de apropriação do mundo são detalhadas, justificando-se desse modo, o uso do termo "campos de experiências” como organizador curricular, na medida em que este preservaria a centralidade da criança e de sua ação no ato pedagógico, o mesmo não ocorrerá no documento final. Nele, “campo de experiência” é tratado em sua dimensão praxiológica, ou seja, como situação de aprendizagem decorrente da intencionalidade do/a professor/a. Visa, nesse sentido, orientar o como fazer, considerando-se os objetivos de aprendizagem definidos para cada campo. Nessa perspectiva, as experiências são consideradas tanto como suportes para as aprendizagens infantis, evocando situações de aprendizagens previamente organizadas pelos adultos/professores e, ao mesmo tempo, expressam também resultados das aprendizagens, previamente previstos.

É nesse sentido, como contexto de aprendizagem intencionalmente organizado, que a concepção de experiência, compreendida então como "experiência educativa”, aproxima-se daquela proposta por Dewey:

[...] el ser humano aprende en la interacción con su ambiente a partir de su capacidad de adaptación funcional, a través del ensayo y error. Ello le permite progresar en la lucha por adaptarse y dominar el ambiente en el que vive. Se aprende por experiencia, mediante la educación por acción («learning by 
doing»). La educación escolar debe por tanto favorecer el diseño de experiencias reales para los estudiantes que supongan a su vez la resolución de problemas prácticos. (RUIZ, 2013, p.107)

De acordo com Dewey, a experiência é meio e condição necessária para que a aprendizagem ocorra; todavia, nem toda experiência resulta em aprendizagens educativas, ou seja, mobilizadoras de mudanças e, portanto, de desenvolvimento. Para que as experiências sejam educativas, o autor pressupõe dois princípios: a) interação e b) continuidade. O primeiro, a interação, diz respeito a necessária adequação das necessidades dos indivíduos às experiências educacionais que lhes são oferecidas; já continuidade diz respeito a relação entre as experiências passadas e as futuras - a eficácia das experiências na modelação da própria subjetividade ou desenvolvimento do educando. É nesse sentido que Dewey afirma que "a mais importante atitude a ser formada é a do desejo de continuar a aprender” (DEWEY, 1976, p. 42). Objetivo similar a este é expresso na consigna da importância do "aprender a aprender”, subjacente também a noção de competências que orienta tanto as indicações curriculares da Itália, como a BNCC no Brasil. Assim, no pensamento de Dewey, no ato educativo tanto é importante a ação ou agir do educando, como também do professor, uma vez que cabe a este a responsabilidade pela organização de situações de aprendizagem que sejam significativas para seus alunos.

Embora Dewey faça referência às condições subjetivas dos educandos como condição necessária ao seu aprendizado, sua concepção de experiência é mais instrumental do que comportamental. Daí a ênfase conferida pelo autor à sistematização de propostas educativas e, logo, de organizações curriculares não fragmentadas, como condição necessária ao desenvolvimento pessoal. Em Dewey, aprendizagem e desenvolvimento são processos que se integram e se transformam mutuamente: “o processo educativo é idêntico ao crescimento [desenvolvimento]” (DEWEY, 1976, p. 27). Aprendizagem e desenvolvimento são processos idênticos; um reflete o outro. Lembramos que esta compreensão da relação entre os processos de aprendizagem e desenvolvimento como "reflexos" um do outro, é sustentada também na psicologia comportamental, tendo sido objeto de críticas de Vigotski.

Das análises que empreendemos tendo como base as diferentes versões da BNCC para a Educação Infantil, sobressai-se essa concepção de experiência - como processo e como fim. A intenção de fazer uma contrapartida aos modelos curriculares referenciados em campos disciplinares, predominantes historicamente na escola, levou seus organizadores a buscar uma forma de organização que atendesse as particularidades dessa etapa educativa. As próprias DCNEI apontam essa necessidade quando definem os currículos como:

Conjunto de práticas que buscam articular as experiências e os saberes das crianças com os conhecimentos que fazem parte do patrimônio cultural, artístico, ambiental, científico e tecnológico, de modo a promover o desenvolvimento integral de crianças de 0 a 5 anos de idade (BRASIL, 2009, p.1). 
Note-se que saberes e experiências são tratados como dimensões diferentes dos processos de apropriação do mundo pelas crianças, cuja articulação com os conhecimentos sistematizados deve ser visada. Na BNCC, mantém-se essa definição como norte, todavia, as experiências passam a ser organizadoras do currículo. Interroga-se sobre essa possibilidade, se com essa perspectiva não se corre o risco de "didatizar" as experiências, sobretudo pela indução provocada pela própria organização da Base: tem-se, primeiro, competências gerais a serem desenvolvidas pelas crianças, desdobradas em direitos de aprendizagem, que por sua vez, para serem alcançados, requerem a organização de situações pedagógicas apropriadas, organizadas em campos de experiências, modelados e orientados pelos objetivos comportamentais previstos para cada campo, em cada recorte etário. Assim, ao tentar resolver o paradoxo dos riscos da disciplinarização, como já dito, predominante nos currículos escolares, gerou-se novas contradições.

Do que tratam enfim, os campos de experiências? Talvez a definição de campos de experiências apresentada na primeira versão da BNCC tenha dado mais conta dessa tarefa, do que as definições posteriores:

As diversas possibilidades de experiências que as crianças podem usufruir, na unidade de Educação Infantil e citados no parecer acima, não ocorrem de modo isolado ou fragmentado, mas são promovidas por um conjunto de práticas que articulam os saberes e os fazeres das crianças com os conhecimentos já sistematizados pela humanidade. Daí a proposta de arranjo curricular para a Educação Infantil na BNC se dar em Campos de Experiências, conjuntos formados considerando alguns aspectos de convergência entre os elementos que os orientam (BRASIL, 2015, p.20. Grifos no original)

Aqui as experiências são tratadas como "possibilidades” (“podem usufruir”) que decorrem dos múltiplos e complexos modos apropriação do mundo, vivenciadas pelas crianças. Já, os “campos de experiências" são definidos "como conjuntos formados”, formulação ainda imprecisa, mas que aponta para o ato pedagógico como totalidade, como “convergência” de saber, fazer e conhecer, cujos sujeitos são adultos e crianças. Nessa perspectiva, as experiências das crianças não são definidoras em si da ação pedagógica, mas constituintes destas.

Em síntese, as ambivalências e contradições que envolvem o termo "campos de experiências" como organizador curricular, resultou da perspectiva de manter a diferenciação da Educação Infantil com relação às demais etapas da Educação Básica, afirmando sua especificidade. A centralidade da criança e as formas próprias de apropriação do mundo, singulares a cada período etário, conduziu as formulações nas duas versões preliminares da BNCC. Nas versões finais (terceira e quarta, aprovada), nota-se um ponto de inflexão com o destaque dado à intencionalidade pedagógica e o reposicionamento dos "campos de experiências" como componentes curriculares, o que é consubstanciado pela definição de objetivos de aprendizagem a cada um destes, e a cada período etário. As críticas elaboradas à I e II versões, por grupos de trabalho e/ou especialistas, coordenados 
pelo Movimento pela Base, apontam como uma fragilidade a falta/pouca intencionalidade pedagógica veiculada por estas versões.

\section{Campos de experiências, objetivos de aprendizagem, faixas etárias: a tecnificação do currículo da Educação Infantil}

Como dissemos anteriormente, a experiência - tratada de forma ambivalente e em duplo sentido, ora como forma de agir das crianças, ora como contextos significativos de aprendizagem, foi transformada em componente curricular, ou seja, em elemento aglutinador de um conjunto de objetivos operacionais que "conversam" sem parcimônia com as competências estabelecidas para a educação básica. Dizendo de outro modo, embora a noção de competências não apareça explicitamente como orientadora das aquisições esperadas como resultados das aprendizagens das crianças, a formulação de objetivos caracterizada em termos de comportamentos esperados, evidencia a lógica que os informa: aquisição de habilidades e evidências de desempenho individuais.

Centrados unicamente nas aquisições das crianças, os objetivos articulados aos campos de experiência repõem a perspectiva tecnicista na Educação Infantil, baseada num enfoque cognitivista e instrumental e, dessa maneira, contrapondo-se às concepções que orientam as Diretrizes Curriculares Nacionais para esta etapa educativa, lembrando a taxionomia dos objetivos educacionais propostos por Benjamin Bloom nos anos de 1960. Ora, este caráter instrumental que se pretende como orientador dos currículos parece-nos, destina-se a instituir um processo de educação das crianças numa lógica bastante próxima daquela dos meios de produção, onde o alicerce é a racionalidade técnica do processo-produto e ênfase posta na eficácia e na produtividade (BEYER; LISTON, 1996). Acredita-se que tecnificando o processo de forma ordenada e sequencial, com objetivos claros, observáveis e, especialmente, mensuráveis, o objetivo final, ou seja, as competências gerais, podem ser alcançadas.

Um objetivo operacional indica o comportamento diretamente observável ou mensurável a ser alcançado ao final de um período ou curso. Assim, no âmbito de cada campo de experiência, que já delimita uma dada abrangência, os objetivos fecham e restringem a atuação pedagógica. Operam nesse universo de possibilidades e no contexto da Educação Infantil desde aquelas perspectivas mais centradas no conhecimento empírico até aquelas voltadas exclusivamente ao conhecimento escolarizado. Nem mesmo os dois eixos articuladores do currículo para essa etapa - interações e brincadeiras - estão imunes à essa lógica, uma vez que o reforço dado aos objetivos de alguns campos de experiências demonstra por onde vão circular as avaliações e, por consequência, o que será priorizado nos materiais didáticos, nos projetos pedagógicos... Ademais, como as competências são da ordem do desempenho individual, apontam somente para as capacidades finais, não envolvem a análise dos processos e percursos implicados, nem mesmo as condições objetivas nas quais foram produzidos os sucessos ou fracassos individuais.

Esta organização curricular para a Educação Infantil que subordina, por assim dizer, os campos de experiências aos objetivos de aprendizagem, foi desenhada desde a primeira 
versão da BNCC, todavia, no percurso desta para a versão aprovada, mudanças substanciais foram feitas. Na primeira versão da BNCC os seis objetivos delimitados por campo de experiências eram mais gerais e contemplavam todo o percurso da etapa sem subdivisões por faixa etária, o que em tese, poderia possibilitar mais autonomia às redes e unidades educativas na definição do currículo e do trabalho docente. Era menos prescritiva e mais aberta e, por essa razão, pouco adequada às avaliações. Isso se altera significativamente a partir da segunda versão com base especialmente nas críticas apresentadas pelo Movimento pela Base:

o documento atribui pouca ênfase a intencionalidade educativa e acaba deixando muito genérica a compreensão de quais são efetivamente as aprendizagens presentes em cada um dos objetivos formulados. Somada a essa preocupação, a ausência de intencionalidades e orientações educativas especificas para as faixas etárias de 0 a 3 anos e de 3 a 5 anos também não contribui para a atuação do professor em vistas a promoção do desenvolvimento e das aprendizagens almejadas. Por fim, destaca-se a importância de incorporar elementos do desenvolvimento da linguagem oral e escrita desde a Educação Infantil, criando as bases para o trabalho de alfabetização no ensino fundamental - além de iniciar também a abordagem de elementos de outras áreas do conhecimento: científico, matemático, conhecimento de mundo (MPB, 2015, p. 15).

Na segunda versão, são propostos então objetivos para três grupos etários em cada campo de experiências, com significativo reforço no número de objetivos que passam de 30 para 73. Paradoxalmente, isso ocorre na versão que incluiu as contribuições vindas dos debates nacionais e da atuação de especialistas da área na redação final deste documento (BNCC - II). Essa perspectiva vai recrudescendo nas versões da BNCC até se consolidar na quarta versão, mantendo a sintonia com as expectativas dos movimentos empresariais que passaram a ser os principais interlocutores do governo federal. Assimilando estas críticas e visando orientar os revisores da segunda versão, o Movimento pela Base publica o documento “Guia de Referência para Redatores”, onde consta:

[...] um ponto de partida útil para identificar a demanda cognitiva adequada para cada nível e para garantir a progressão de aprendizagem através de utilização de verbos é a Taxonomia de Bloom revisada. Esta taxonomia fornece um modelo dinâmico para classificar processos intelectuais, usados pelos alunos na aquisição e uso dos conhecimentos (MPB, s/d, p.15)

Ademais, a delimitação de três grupos etários - bebês (0 a 18 meses), crianças bem pequenas (19 meses a 3 anos e 11 meses), crianças pequenas (4 anos a 5 anos e 11 meses) para cada campo de experiências, facilitou ainda mais a lógica dos objetivos operacionais pelos parâmetros de progressão e intensidade das ações. A seleção e a organização de um conjunto de objetivos operacionais, por meio dos quais se depreendem conhecimentos por faixa etária e com graduação de complexidade, constitui um arranjo curricular característico 
dos processos de escolarização. Essa métrica justíssima de progressão das aprendizagens e do desenvolvimento apresenta aderência aos testes de acompanhamento do desenvolvimento das crianças, da retomada das fichas de avaliação de desempenho e acenam à normalização da infância e do desenvolvimento. Retrocesso!

Ajustes na redação com foco nos objetivos operacionais, incremento nos objetivos relativo às áreas de linguagem oral e escrita e matemática, homogeneidade e normalização da infância, avaliações em larga escala são argumentos suficientemente fortes à tese da escolarização da Educação Infantil. Somada a essas questões consta também os interesses dos empresários da educação na produção de materiais didático-pedagógicos voltados à alfabetização precoce e consequente disciplinamento dos corpos exigido pelo uso das apostilas e livros didáticos.

\section{Considerações finais}

Como procuramos mostrar, a Educação Infantil permanece como um campo de litígios, estando no centro deste diferentes perspectivas para a educação das crianças pequenas. Não obstante os esforços para se construir uma BNCC que afirmasse a especificidade desta etapa educativa, diferenciando-se em relação à organização curricular proposta para o ensino fundamental, pode acabar reforçando os propósitos de um projeto educativo centrado em competências e propenso à escolarização.

A busca de continuidade com o ensino fundamental pode reverberar no reforço do caráter preparatório da Educação Infantil, ainda que não propriamente antecipatório, no sentido de "trazer" os conteúdos do EF para esta etapa. A lógica da continuidade dá-se pela integração entre as competências gerais - da Educação Básica -, a relação destas com os direitos de aprendizagem e destes, com os campos de experiências e objetivos de aprendizagem para as distintas faixas etárias. Estes objetivos, estabelecidos de antemão, funcionam como um "guia" para a elaboração dos planejamentos e orientação da prática pedagógica. Corre-se o risco de passarem a ser engessados e rígidos, ao invés de flexíveis, como requer uma ação pedagógica centrada na criança. Embora toda a legislação voltada para a Educação Infantil se fundamente no objetivo da promoção do desenvolvimento integral das crianças, o que vemos são alguns "campos de experiências" serem priorizados em detrimento de outros. Não por acaso, exatamente aqueles considerados mais vinculados e preparatórios para a alfabetização e o conhecimento matemático.

A BNCC, embora negue textualmente em todas as versões, constituiu um currículo nacional. A definição de um conjunto de $60 \%$ dos objetivos de ensino e aprendizagem para todas as áreas e componentes curriculares das etapas de Educação Infantil e Ensino Fundamental, não deixa dúvidas. Há um claro recorte de conhecimentos explicitados nos objetivos operacionais que constituem a fonte principal das avaliações em larga escala. Além disso, os parâmetros utilizados para definir o que comporia os $60 \%$ não foram claramente explicitados e, segundo análise de professores das redes públicas, em comparações realizadas entre a BNCC e os currículos praticados antes dela, esse percentual 
significa mais de cem por cento do que era trabalhado, ou seja, mais do que é possível dar conta no espaço-tempo curricular de cada ano letivo. Significa assinalar, em primeiro lugar, a quase impossibilidade de acrescer mais $40 \%$ de “conteúdos” relativos às especificidades locais e, em segundo, que o caráter obrigatório dos $60 \%$ somado à sua vinculação com os mecanismos de avaliação em larga escala acabam por restringir as possibilidades de diferenciação e servem para afirmar a BNCC como currículo nacional.

Se a referência é a de que as redes, as escolas de infância, a infância e as crianças são multiplicidade e "a multiplicidade é sempre heterogênea [...] o que se fere imediatamente na tentativa de homogeneização é a diferença.” (ABRAMOWICZ, CRUZ, MORUZZI, 2016, p.48). Uma base unificada instaura um modelo. Ademais, as forças em disputa tanto pelo conteúdo da Base como pelas formas de sua implantação são extremamente desiguais, isso "significa que o movimento social ou as concepções não escolarizadas para a Educação Infantil não têm a mesma força/poder político e econômico da concepção privatista da educação” (Idem., p.51) que não compreende a infância para além da escolarização. O alinhamento com outras políticas (BRASIL, 2017, p.6) anunciado já nas primeiras páginas da BNCC aprovada, não se dá ao acaso. Logo, a obrigatoriedade posta às redes vai produzir demandas de cursos de formação, de materiais didáticos, de assessorias. Com tantos interesses em cena dificilmente teremos como retroceder, porém, a resistência é sempre possível, mesmo nos contextos mais extremos. Resistiremos!

\section{Notas}

1. Os PCN e RCNEI foram iniciativas do Governo de Fernando Henrique Cardoso, coetâneas da primeira versão das diretrizes curriculares nacionais para todas as etapas da Educação Básica.

2. O Programa Currículo em Movimento foi lançado pelo Ministério da Educação e Cultura (MEC) em 2009, no Governo de Luiz Ignácio Lula da Silva, com o objetivo de revisar as diretrizes para todas as etapas e modalidades da Educação Básica.

3. Essa questão, segundo Macedo (2015) também esteve presente nas discussões relativas ao PNE e foi levantada pelos representantes das entidades científicas da área da educação.

4. No documento "Por uma política curricular para a educação básica: contribuição ao debate da base nacional comum a partir do direito à aprendizagem e ao desenvolvimento" (BRASIL, 2014), consta a relação dos membros do Grupo de Trabalho. O documento preliminar apresentado por esse GT, em 2014, foi desconsiderado como uma possível primeira versão da BNCC, embora seu teor tenha reverberado nas comissões subsequentes.

5. À frente dos trabalhos da Base para a educação infantil estavam: Maria Carmen Silveira Barbosa, Silvia Helena Vieira Cruz, Zilma de Moraes Ramos de Oliveira e Paulo Sergio Fochi.

6. No contexto do governo de Michel Temer, a partir de maio de 2016, logo após a apresentação da BNCC-II, as equipes do MEC foram substancialmente alteradas, atuando nestas mudanças a professora Maria Helena Guimarães de Castro, então Secretaria Executiva do mesmo e presidente do Comitê Gestor responsável pela implementação da BNCC.

7. Disponível em: http://movimentopelabase.org.bor/wp-content/uploads/2017/03/IndiceLeiturasCriticasRed.pdf Acesso em: 25 de nov. 2018.

8. http://jeduca.org.br/texto/webinario-analisa-as-ultimas-mudancas-na-bncc

9. Sobre a produção acadêmica a respeito da formação por competências - primeira metade dos anos 2000.

10. A ideia de campos de experiências como organizadores do currículo da Educação Infantil também está presente em outros países. Na Itália, a organização curricular por campos de experiencias está prevista no documento de Indicação Nacional Italiana (1991), posteriormente revisado na legislação de 2012. Nessa mesma direção, a BNCC estrutura-se a 
partir dos “Campos de Experiencias”, reorganizando e ampliando, em cada um deles, os objetivos indicados no artigo $9^{\circ}$ das DCNEI. (BNCC, 2016, p. 63)

\section{Referências}

ABRAMOWICZ, A.; CRUZ, A. C. J.; MORUZZI, A. B. Alguns apontamentos: a quem interessa a base nacional comum curricular para a educação infantil? Debates em Educação. Maceió, Vol. 8, nº 16, Jul./Dez. 2016.

AGUIAR, M. A. S. Política educacional e a base nacional comum curricular: o processo de formulação em questão. Currículo sem Fronteiras, v. 18, n. 3, p. 722-738, set./dez. 2018.

BARBOSA, M. C. S.; RICHTER, S. R. S. Campos de Experiência: uma possibilidade para interrogar o currículo. In: FINCO, Daniela; BARBOSA, Maria Carmen Silveira \& FARIA, Ana Lucia Goulart (ed.). Campos de experiências na escola da infância: contribuições italianas para inventar um currículo de Educação Infantil brasileiro (p. 221-232). Campinas: Edições Leitura Crítica, 2015.

BARDIN, Laurence. Análise de conteúdo. Lisboa: Edições 70, 1979.

BEYER, E. L.; LISTON, D. P. Curriculum in conflict: social visions, educational agendas and progressive school reform. New York: Teachers College Press, 1996.

BRASIL. Lei 13.005, de 25 de junho de 2014. Aprova o Plano Nacional de Educação. Diário Oficial da União - Seção 1 - Edição Extra - 26/6/2014, página 1.

BRASIL. MEC. CONSED. UNDIME. Base Nacional Comum Curricular. Proposta preliminar. Primeira versão. MEC/Consed/ Undime, setembro de 2015, 302p.

BRASIL. MEC. CONSED. UNDIME. Base Nacional Comum Curricular. Proposta preliminar. Segunda versão revista. MEC/Consed/Undime, abril de 2016, 652p.

BRASIL. Conselho Nacional de Educação. Base Nacional Comum Curricular. Proposta homologada. MEC/Consede/Undime, dezembro de 2017a, 468p.

BRASIL. Conselho Nacional de Educação. Resolução CNE/CP 2/2017. Institui e orienta a implantação da Base Nacional Comum Curricular, a ser respeitada obrigatoriamente ao longo das etapas e respectivas modalidades no âmbito da Educação Básica. Diário Oficial da União, Brasília, 22 de dezembro de 2017b, Seção 1, pp. 41 a 44.

BRASIL. MEC. Portaria n 1.570/2017. Homologa o Parecer CNE/CP nº 15/2017, do Conselho Pleno do Conselho Nacional de Educação e o Projeto de Resolução a ele anexo, instituem e orientam a implantação da Base Nacional Comum Curricular - BNCC. Diário Oficial da União de 21/12/2017c, Seção 1, Pág. 146.

BRASIL. MEC. CONSED. UNDIME.MPB. Base Nacional Comum Curricular. Terceira versão. MEC/Consed/Undime/MPB, abril de 2017d, 396p.

CURY, Carlos Roberto Jamil. Educação e direito à educação no Brasil: Um histórico pelas Constituições. Belo Horizonte: Mazza Edições, 2014.

DEWEY, J. Experiência e educação. São Paulo: Editora Nacional, 1976.

DURLI. Z. Histórico de construção da BNCC Florianópolis, 2018. Relatório do projeto de pós-doutoramento. Florianópolis, 2019.

FREITAS, L. C. Os reformadores empresariais da educação: da desmoralização do magistério à destruição do sistema público de educação. Educação \& Sociedade (Impresso), v. 33, p. 379-404, 2012. Disponível em http://www.scielo.br/pdf/es/v33n119/a04v33n119.pdf. Acesso em 05/12/2018. 
FOCHI, Paulo Sérgio. Ludicidade, continuidade e significatividade nos campos de Experiência. In: FINCO, Daniela; BARBOSA, Maria Carmen Silveira \& FARIA, Ana Lucia Goulart (ed.). Campos de experiências na escola da infância: contribuições italianas para inventar um currículo de Educação Infantil brasileiro (p. 221-232). Campinas: Edições Leitura Crítica. 2015.

JEDUCA. Webinário analisa as últimas mudanças na BNCC. Entrevista com Ivan Claudio Siqueira, do Conselho Nacional de Educação. JEDUCA, Brasília, 01 dez. 2017. Disponível em: http://jeduca.org.br/texto/webinario-analisa-as-ultimas-mudancas-na-bncc. Acesso em: 15 set. 2018.

MACEDO, Elizabeth. Base Nacional Comum para currículos: direitos de aprendizagem e desenvolvimento para quem? Educação \& Sociedade., Campinas, v. 36, nº. 133, p. 891-908, out.-dez., 2015. (p.891-908)

MOVIMENTO PELA BASE (MPB). Leitura crítica da base - Balanço preliminar. Dezembro de 2015. Disponível em: http://movimentopelabase.org.br/wp-content/uploads/2015/12/BNC_leitura_critica_ Movimento_dez_15MEC_VF.pdf. Acesso em: 10 nov. 2018

MOVIMENTO PELA BASE (MPB). Guia de referência para o planejamento e redação de objetivos de aprendizagem. s/d. Disponível em: http://movimentopelabase.org.br/wp-content/uploads/2017/03/Guiade-Refer\%C3\%AAncia-para-reda\%C3\%A7\%C3\%A3o-de-objetivos-de-aprendizagem.pdf. Acesso em: 22 nov. 2018.

PEREIRA, R. S. A política de competências e habilidades na educação básica pública: relações entre Brasil e OCDE. Tese (Doutorado - Doutorado em Educação) -Universidade de Brasília, 2016. 284 p.

RUIZ, G. La teoría de la experiencia de John Dewey: significación histórica y vigencia en el debate teórico contemporâneo. Revista Foro de Educación. v. 11, n. 15, enero-diciembre 2013, pp. 103-124

TYLER, R. Princípios básicos de currículo e ensino. Porto Alegre: Globo, 1974.

XIMENES, Salomão. Direito à Qualidade na Educação Básica: teoria e crítica. São Paulo: Quartier Latin, 2014.

\section{Correspondência}

Roselane Fátima Campos: Doutora em Educação. Docente do Departamento de Metodologia de Ensino da Universidade Federal de Santa Catarina (UFSC).

E-mail: roselane.campos@gmail.com

Zenilde Durli: Doutora em Educação. Docente do Departamento de Metodologia de Ensino e do Programa de Pós-Graduação em Educação da Universidade Federal de Santa Catarina (UFSC).

E-mail: zenildedurli63@gmail.com

Texto publicado em Currículo sem Fronteiras com autorização das autoras 